\title{
Vajinal enfeksiyon varlığı ve tipinin kadında cinsel yașama etkisi
}

\author{
The effect of vaginal infection and type on women's sexual life
}

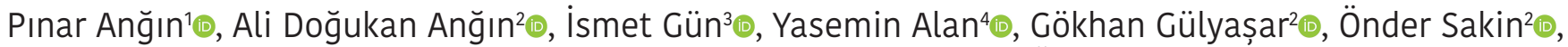 \\ Resul Karakuș ${ }^{\circ}$, Süleyman Eserdağ ${ }^{6} \odot$, Vildan Elibol7 ${ }^{7}$, Abdülmecit Öktem ${ }^{8} \odot$
}

\section{öz} fonksiyonlarını değerlendirmeyi amaçladık. Bizim bildiğimiz kadarıyla, en sık görülen üç farklı ajanın kadın cinsel fonksiyonları üzerine etkisini değerlendiren ilk prospektif çalışmadır.

GEREÇ ve YÖNTEMLER: Prospektif non-randomize çalışmamızda vajinal akıntı şikâyetiyle başvuran 230 hastadan pap-smear alındı. Papsmear sonucu normal veya inflamasyon olarak raporlanan hastalar kontrol grubunu (Grup 1, n: 122) oluştururken trikomonas (Grup 2, n: 27), bakteriyel vajinozis (BV) (Grup 3, n: 40) ve kandidiyazis olarak raporlanan hastalar (Grup 4, n: 41) çalışma grubunu oluşturdu. Toplam skorun $\leq 26,55$ olması kadın seksüel disfonksiyonu (FSD) olarak kabul edildi.

BULGULAR: Gruplar total FSFI ve subgruplar olan istek, uyarılma, ıslanma, orgazm, tatmin, ağrı skorları açısından ve toplam FSD hasta sayıları açısından karşılaştırıldığında istatiksel olarak anlamlı bir fark saptanmadı $(\mathrm{p}>0,05)$. Koku, renkli akıntı (beyaz, sarı, yeşil) ve kaşıntı tarifleyen hasta sayısı Grup 1'de istatiksel anlamlı olarak yüksek tespit edildi $(p<0,01)$. Lojistik regresyon analizinde beyaz renkli vajinal akıntı, eğitim seviyesi (ortaokul ve lise) ve çalışıyor olmak FSD için risk faktörü olarak belirlendi.

SONUÇ: Vajinal akıntıya neden olan trikomonas, BV ve kandidiyazisin görüldü. Günümüzde vajinal akıntının FSD'ye neden olduğu konusu hala netlik kazanmamıştır.

Anahtar Kelimeler: vajinit, trikomonas, bakteriyel vajinozis, kandida, FSFI, FSD
AMAÇ: Vajinal akıntıya neden olan enfeksiyon ajanına göre kadın cinsel kadın cinsel fonksiyonları üzerinde, FSD açısından bir fark yaratmadığı

\section{ABSTRACT}

OBJECTIVE: We aimed to evaluate female sexual function according to the infective agent causing a vaginal discharge. To the best of our knowledge, this is the first study to evaluate the effects of 3 different agents on female sexual function.

MATERIAL and METHODS: In this prospective, nonrandomized study, a pap-smear was taken from 230 patients who presented with complaints of vaginal discharge. The patients were separated into groups according to the pap-smear results. Patients that presented as normal or with inflammation formed the control group (Group 1, n: 122), and study groups were formed of those presenting with trichomonas (Group 2, n: 27), bacterial vaginosis (Group 3, n: 40) and candidiasis (Group 4, n: 41). Patients with a total score of $\leq 26.55$ were classified as having a female sexual dysfunction.

RESULTS: No statistically significant difference was determined between the groups with respect to total female sexual function index scores and the subdimensions of desire, arousal, wetness, orgasm, satisfaction and pain, and the total number of female sexual dysfunction patients $(\mathrm{p}>0.05)$. The number of patients with odorous, colored discharge (white, yellow, green) and itching was significantly higher in Group 1 than in the other groups $(p<0.01)$. In the logistic regression analysis, risk factors for female sexual dysfunction were determined as white-colored vaginal discharge, an education level (middle school and high school) and employment.

CONCLUSION: Vaginal discharge caused by trichomonas, bacterial vaginosis, and candidiasis was not observed to have any effect on female sexual function. There is still no clarification on the subject of vaginal discharge causing female sexual dysfunction.

Keywords: vaginitis, trichomonas, bacterial vaginosis, candidiasis, FSFI, FSD

\section{GiRiș}

${ }^{2}$ Sağlık Bilimleri Üniversitesi, Lütfi Kırdar Eğitim Araşırma Hastanesi, Kadın Hastalıkla ve Doğum Kliniği, İstanbul, Türkiye

${ }^{3}$ Yakın Doğu Üniversitesi Tıp Fakültesi, Kadın Hastalıkları ve Doğum Anabilim Dalı, Kıbrıs ${ }^{4}$ izmir Büyükşehir Belediyesi Eşrefpaşa Hastanesi, İzmir, Türkiye

${ }^{5}$ Zeynep Kamil Kadın Hastalıkları ve Çocuk Eğitim ve Arastırma Hastanesi, İstanbul, Türkiye

${ }^{6}$ Hera Kadın Sağlığı Merkezi, Ankara, Türkiye

${ }^{7}$ Sağlık Bilimleri Üniversitesi, Lütfi Kırdar Eğitim Araştırma Hastanesi, Patoloji Kliniği, İstanbul, Türkiye

${ }^{8}$ Sağlık Bakanlığı, Şırnak Cizre Devlet Hastanesi, Kadın Hastalıkları ve Doğum Kliniği, Şırnak, Türkiye

\section{Yazıșma Adresi/ Correspondence:}

Uzm. Dr. Yasemin Alan

İzmir Büyükşehir Belediyesi Eşrefpaşa Hastanesi Kadın Hastalıkları ve Doğum Kliniği,

35110 Izmir, Türkiye

Tel: $\quad$ +905333952068

E-mail: jasminalann@hotmail.com

Geliș/ Received: $\quad 16.08 .2020$

Kabul/ Accepted: $\quad 21.10 .2020$
Jinekoloji polikliniklerine başvurularda en sık şikâyetlerden birisi vajinit nedeniyle oluşan vajinal akıntıdır. ${ }^{[1]}$ Sebep çoğunlukla bakteriyel vajinozis (BV), trikomonas vajinalis veya kandidal enfeksiyonlardır. ${ }^{[2]}$ Vajinit oluşturduğu akıntı, koku, kaşıntı, yanma ve acı nedeniyle yaşam kalitesini olumsuz etkiler. Enfeksiyon ajanları benzer semptomlara neden olsa da ajana özgü değişiklikler gösterirler. Genelde BV balık kokulu beyaz grimsi bir akıntıya; trikomanas kaşıntılı, yanmalı kötü kokulu yeşilimsi bir akıntıya; kandidiyazis beyaz kokusuz küf şeklinde bir akıntıya neden olur. ${ }^{[3]}$ Dolayısıyla akıntı etkenine göre gelişen şikayetler de değişken olabilir. 
Vajinal enfeksiyon ve oluşan akıntı cinsel fonksiyonları etkileyebilir. Kadınlarda yaygın olarak görülen cinsel işlev bozukluğunun birçok farklı psikolojik ve fizyolojik nedeni vardır ve bunlardan biri vajinal akıntıdır. ${ }^{[4,5]}$ Vajinitte ağrı ve koku cinsel yaşamı olumsuz etkileyebilir. ${ }^{[6,7]}$ Trikomonas nedeniyle vajinitte disparoni ortaya çıkabilir. ${ }^{\left[{ }^{[8]}\right.}$ Cinsel işlev bozukluğunu değerlendirmek için geliştirilmiş bazı puanlama sistemleri vardır. ${ }^{[9]}$ En sık kullanılan sistemlerden biri, Türkçe geçerliliği olan kadın cinsel işlev indeksidir (FSFI). ${ }^{[10]}$

Biz çalışmamızda, vajinal akıntının kadın cinsel fonksiyonlarına olan etkisinin non-enfeksiyöz ve enfeksiyona neden olan ve en sık görülen üç ajanın tipine göre nasıl değiştiğini incelemek istedik.

\section{GEREC VE YÖNTEMLER}

2017 Ocak ve 2018 Mayıs tarihleri aralığında, Eğitim ve Araştırma Hastanesi kadın hastalıkları ve doğum kliniği jinekoloji polikliniklerine, rahatsız edici vajinal akıntı şikâyetiyle başvuran ve geçmiş 1 yıl içinde aktif cinsel yaşamı olan hastalar çalışmaya dâhil edildi. Prospektif non-randomize şekilde yaptığımız çalışma için Eğitim ve Araştırma Hastanesi etik kurulundan onay alındı (Etik kurul no: 2016/514/88/12).

Hastalar gebe veya lohusa iseler, vajinal cerrahi öyküsü varsa, histerektomi ve/veya bilateral salpingo-ooferektomi öyküsü varsa, kısırlık tedavisi görüyorsa, menopozda ise veya FSFI sorularına tam olarak cevap veremiyorsa çalışmadan çıkarıldı. Örneklem büyüklüğü için, alfa hata düzeyi 0,05 ve beta hata düzeyi 0,1 olan -230 katılımcının gerekli olacağını hesaplandı (Şekil 1).

Tüm katılımcılardan yazılı imzalı bir bilgilendirilmiş onam formu alındı. Öncelikle uzman bir jinekolog tarafından her hasta için ayrıntılı bir muayene yapıldı; muayene parametreleri yaş, boy, kilo, gravida ve parite, önceki doğumların türü, meslek, ortalama aile gelir düzeyi, şikayet süresi, anormal koku (cinsel ilişki sırasında kötü koku veya artan koku olarak tanımlanır), kaşıntı, herhangi bir

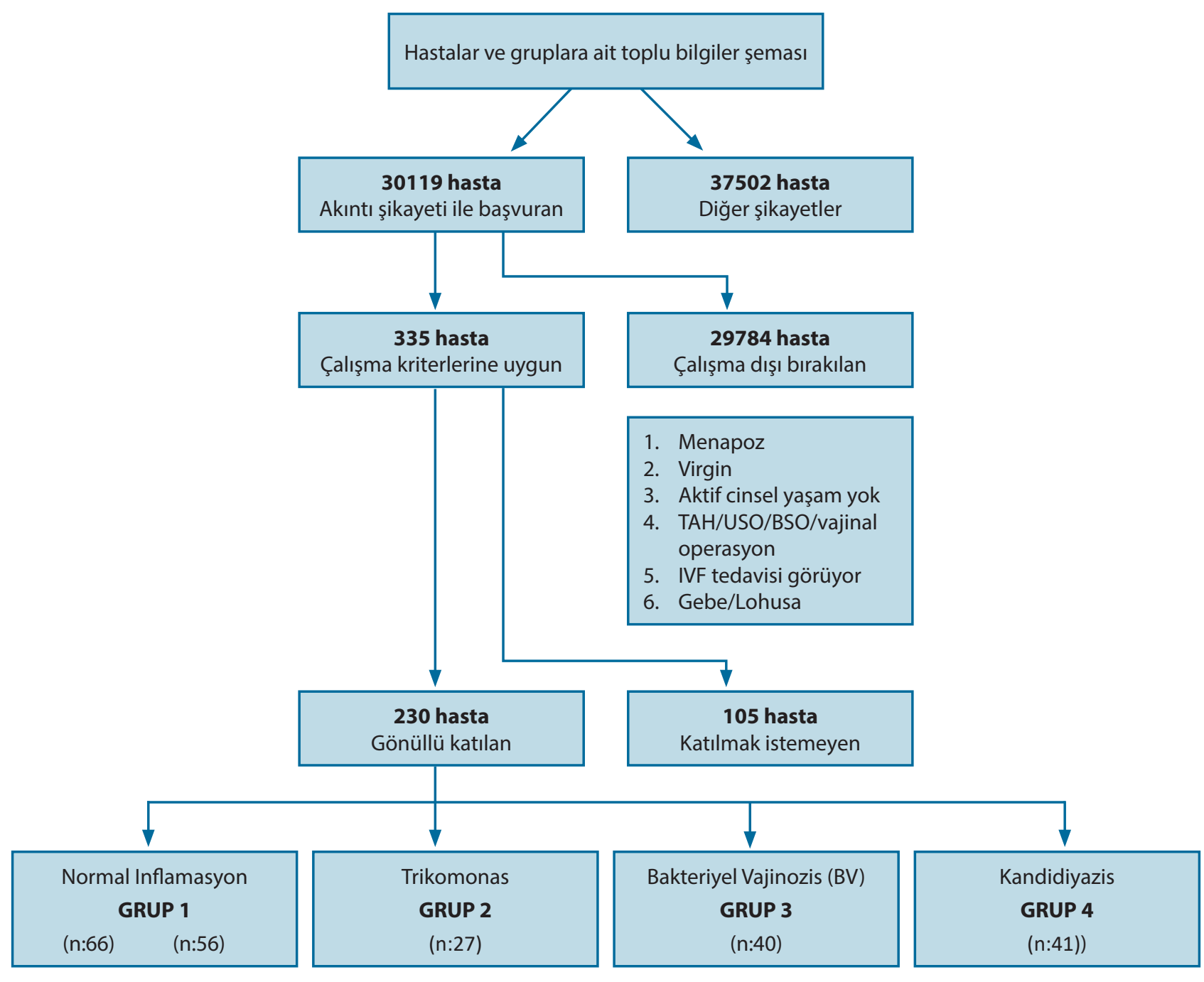

Şekil 1. Hastalar ve gruplara ait toplu bilgiler şeması 
kontrasepsiyon veya korunma yöntemi ve dismenore durumu şeklindeydi.

Daha sonra jinekoloji masasında spekulum muayenesi yapılarak akıntı rengi (renksiz, beyaz, yeşil, sarı) ve karakteri (bozulmuş balık kokusu, çilek benzeri görünüm, yoğun mikotik görünüm, vulvar hiperemi vb.) kaydedildi. Papsmear alındı ve uzman bir patolog tarafından incelenmek üzere patoloji laboratuvarına gönderildi. Son olarak hastadan son bir ay içindeki cinsel yaşamını gözden geçiren 19 maddelik FSFI anketini özel bir odada tek başına doldurması istendi. Anket muayene ile akıntı tespit edildikten sonra herhangi bir tedavi başlanmadan önce dolduruldu. FSFI'nin Türkçe validasyonu yapılmıştır. ${ }^{[11,12]}$ Hasta verilerinin gizliliği için sonuçlar yalnızca numara ve baş harflerle kaydedildi. Pap-smear örnekleri akıntı ajanına göre değerlendirildi ve aynı patoloji uzmanı tarafından kaydedildi. [13-17] Patolog klinik verilere karşı kördü.

Hastalar pap-smear sonuçlarına ve vajinal spekulum muayene özelliklerine göre gruplara ayrıldı. Normal veya enflamasyon ile başvuran hastalar kontrol grubunu oluştururken (Grup 1, n: 122) çalışma grupları ise trikomonas (Grup 2, n: 27), bakteriyel vajinozis (BV) (Grup 3, n: 40) ile kandidiyazis (Grup 4, n: 41) şeklinde oluşturuldu.

Yaş, vücut kitle indeksi (VKİ), doğum sayısı, doğum türleri, çocuk sayısı, gebeliği önleme ve korunma yöntemleri, dismenore, meslek, gelir düzeyi, taburculuk süresi ve koku, kaşıntı ve taburculuk rengi değerlendirildi ve değiştirici veya karıştırıcı etkenler olarak kullanıldı. FSFI sonuçları gruplar arasında karşılaştırıldı. FSFI verileri, arzu, uyarılma, sslaklık, orgazm, memnuniyet, ağrı ve toplam puan olmak üzere 7 başlık altında kategorize edildi. Toplam puanı 26,55 ve altında olan hastalar kadın cinsel işlev bozukluğu (FSD) olarak sınıflandırıldı.

\section{İstatistiksel Analiz}

Verilerin değerlendirilmesinde SPSS 20 (IBM Corp. Released 2011. IBM SPSS Statistics for Windows, Version 20.0, Armonk, NY: IBM Corp.) istatistik paket programı kullanılmıştır. Değişkenler ortalama \pm standart sapma ve Medyan (Maksimum-Minumum) yüzde ve frekans değerlerleriyle kullanılmıştır. Değişkenlerin dağılımı Kolmogorov-Smirnov ve Shapiro-Wilk testleri ile değerlendirildi. Sadece BMI normal dağılım gösteriyorken diğer parametrelerin hiçbiri normal dağılım göstermiyordu. Üç ve daha fazla grup karşılaştırması için normalite testine uygun parametreler için Tek Yönlü Varyans Analizi ve çoklu karşılaştırma testlerinden Tukey HSD testi, ön şartlar sağlanmadığında ise Kruskal-Wallis ve çoklu karşılaştırma testlerinden Bonferroni-Dunn testi kullanılmıştır. Grup kategorik karşılaştırmaların hepsi ki-kare testi ile yapıldı. Testlerin istatistiksel anlamlılık düzeyi için $\mathrm{p}<0,05$ değeri kabul edilmiştir.

Sürekli iki değişken arasındaki ilişki Pearson Korelasyon Katsayısı ile parametrik test ön şartlarını sağlamadığı durumda ise Spearman Korelasyon Katsayısı ile değerlendirilmiştir. Effectmodifier veya confounder etkisi için lojistik regresyon analizi kullanılmıştır. Oluşturulan modelin açıklayıcılığı için Cox\&Snell veya Nagelkerke R kare değerleri kullanılmış ve "sig" değerinin 0,05'den büyük olması modelin iyi bir model olduğuna karar vermemizi sağlamıştır. Testlerin istatistiksel anlamlılık düzeyi için $\mathrm{p}<0,05$ değeri kabul edilmiştir.

\section{BULGULAR}

Toplam hasta sayısı 230 olup; Grup 1, 122 hastadan; Grup 2, 27 hastadan; Grup 3, 40 hastadan; Grup 4, 41 hastadan oluşturuldu. Total grubun yaş ortalaması $36,7 \pm 9,3$ ve VKİ 25,8 44,6 idi. Çalışmaya katılan 230 hastanın demografik özellikleri ve gruplar arasında karşılaştırılması Tablo 1'de gösterilmiştir. Dört grup arasında demografik özellikler açısından istatiksel olarak anlamlı fark izlenmemiştir $(\mathrm{p}>0,05)$.

Gruplar koku, kaşıntı ve renk değişikliği dağılımı açısından incelendiğinde rahatsız edici kokuya sahip hasta sayısının, renkli (beyaz, sarı, yeşil) akıntıya sahip hasta sayısının ve kaşıntı yakınması olan hasta sayısının Grup 1'de istatiksel anlamlı olarak daha fazla olduğu görülmektedir $(\mathrm{p}<0,01)$.

Gruplar kendi aralarında total FSFI, istek, uyarılma, sslanma, orgazm, tatmin, ağrı skorları açısından ve FSD hasta sayıları açısından karşılaştırıldığında gruplar arasında istatiksel anlamlı fark saptanmadı ( $\mathrm{p}>0,05)$ (Tablo 2).

Total FSFI skoru $\leq 26,55$ ve $>26,55$ olan hastalara lojistik regresyon analizi uygulanarak faktörlerin ODD ratio değerleri hesaplandığında FSD'nin beyaz renk akıntıya sahip olanlarda beş kat daha fazla olduğu (p: 0,019), eğitim seviyesi ortaokul ve lise düzeyinde olanlarda 3,8 kat fazla olduğu (p: 0,03), iş sahibi olan hasta grubunda ise 1,5 kat fazla olduğu görülmektedir (p: 0,017) (Tablo 3).

Gruplar koku, kaşıntı ve renk değişikliği dağılımı açısından incelendiğinde rahatsız edici kokuya sahip hasta sayısının, renkli (beyaz, sarı, yeşil) akıntıya sahip hasta sayısının ve kaşıntı tarifleyen hasta sayısının grup 1'de istatiksel anlamlı olarak daha fazla olduğu görülmektedir $(\mathrm{p}<0,01)$ (Tablo 4). 
Tablo 1. Gruplar arası demografik özelliklerin karşılaştırılması

\begin{tabular}{|c|c|c|c|c|c|c|c|}
\hline Parametreler & & $\begin{array}{c}\text { GRUP } 1 \\
\text { Kontrol (n:122) }\end{array}$ & $\begin{array}{c}\text { GRUP } 2 \\
\text { Trikomonas (n:27) }\end{array}$ & $\begin{array}{c}\text { GRUP } 3 \\
B V(n: 40)\end{array}$ & $\begin{array}{c}\text { GRUP } 4 \\
\text { Kandida (n:41) }\end{array}$ & Total (n:230) & $p$ \\
\hline Yaş (yıl) & & $37,3 \pm 9,8$ & $38,0 \pm 7,8$ & $35,4 \pm 8,8$ & $35,3 \pm 9,3$ & $36,7 \pm 9,3$ & $0,458^{a}$ \\
\hline BMI $\left(\mathrm{kg} / \mathrm{m}^{2)}\right.$ & & $26,6 \pm 5$ & $25,4 \pm 4$ & $26,5 \pm 3,8$ & $24,5 \pm 4,7$ & $25,8 \pm 4,6$ & $0,205^{a}$ \\
\hline Gravida (n) & & $2 \pm 1,4$ & $2,5 \pm 1,7$ & $2,3 \pm 1,7$ & $2,1 \pm 1,5$ & $2,1 \pm 1,5$ & $0,515^{a}$ \\
\hline Parite (n) & & $1,7 \pm 1,2$ & $2,1 \pm 1,3$ & $2 \pm 1,5$ & $1,9 \pm 1,5$ & $1,8 \pm 1,3$ & $0,347^{a}$ \\
\hline \multirow{2}{*}{$\begin{array}{l}\text { Dismenore } \\
(n, \%)\end{array}$} & var & $24(10,4)$ & $10(4,3)$ & $14(6,1)$ & $11(4,8)$ & $59(25,7)$ & \multirow{2}{*}{$0,112^{b}$} \\
\hline & yok & $98(7,4)$ & $17(7,4)$ & $26(11,3)$ & $30(13)$ & $171(74,3)$ & \\
\hline \multirow{4}{*}{$\begin{array}{l}\text { Doğum } \\
(n, \%)\end{array}$} & yok & $20(8,7)$ & $2(0,9)$ & $4(1,7)$ & $8(3,5)$ & $34(14,8)$ & \multirow{4}{*}{$0,785^{b}$} \\
\hline & NSD & $68(29,6)$ & $16(7)$ & $22(9,6)$ & $20(8,7)$ & $126(54,8)$ & \\
\hline & SC & $23(10)$ & $8(3,5)$ & $11(4,8)$ & $9(3,9)$ & $51(22,2)$ & \\
\hline & $\mathrm{NSD}+\mathrm{SC}$ & $11(4,8)$ & $1(0,4)$ & $3(1,3)$ & $4(1,7)$ & $19(8,3)$ & \\
\hline \multirow{5}{*}{$\begin{array}{l}\text { Korunma yöntemi } \\
(n, \%)\end{array}$} & yok & $57(24,8)$ & $14(6,1)$ & $15(6,5)$ & $15(6,5)$ & $101(43,9)$ & \multirow{5}{*}{$0,537^{b}$} \\
\hline & oks & $8(3,5)$ & 0 & $3(1,3)$ & $4(1,7)$ & $15(6,5)$ & \\
\hline & kondom & $24(10,4)$ & $5(2,2)$ & $4(1,7)$ & $7(3)$ & $40(17,4)$ & \\
\hline & RiA & $26(11,3)$ & $7(3)$ & $16(7)$ & $11(4,8)$ & $60(26,1)$ & \\
\hline & Tüp lig. & $7(3)$ & $1(0,4)$ & $2(0,9)$ & $4(1,7)$ & $14(6,1)$ & \\
\hline \multirow{3}{*}{$\begin{array}{l}\text { Eğitim seviyesi } \\
(n, \%)\end{array}$} & $\leq$ ilkokul & $67(29,1)$ & $16(7)$ & $20(8,7)$ & $18(7,8)$ & $121(52,6)$ & \multirow{3}{*}{$0,481^{b}$} \\
\hline & ortaokul/lise & $36(15,7)$ & $8(3,5)$ & $17(7,4)$ & $18(7,8)$ & $79(34,3)$ & \\
\hline & $\geq$ üniversit & $19(8,3)$ & $3(1,3)$ & $3(1,3)$ & $5(2,2)$ & $30(13)$ & \\
\hline \multirow{3}{*}{$\begin{array}{l}\text { Meslek } \\
(n, \%)\end{array}$} & memur & $27(11,7)$ & $4(1,7)$ & $7(3)$ & $6(2,6)$ & $44(19,1)$ & \multirow{3}{*}{$0,735^{b}$} \\
\hline & işçi & $16(7)$ & $5(2,2)$ & $9(3,9)$ & $6(2,6)$ & $36(15,7)$ & \\
\hline & işsiz & $79(34,3)$ & $18(7,8)$ & $24(10,4)$ & $29(12,6)$ & $150(65,2)$ & \\
\hline \multirow{3}{*}{$\begin{array}{l}\text { Ortak gelir seviyesi } \\
\text { TL }(n, \%)\end{array}$} & $<1400$ & $33(14,3)$ & $6(2,6)$ & $6(2,6)$ & $6(2,6)$ & $51(22,2)$ & \multirow{3}{*}{$0,461^{b}$} \\
\hline & $1401-2500$ & $59(25,7)$ & $14(6,1)$ & $26(11,3)$ & $23(10)$ & $122(53)$ & \\
\hline & $>2501$ & $30(13)$ & $7(3)$ & $8(3,5)$ & $12(5,2)$ & $57(24,8)$ & \\
\hline
\end{tabular}

Veriler ortalama \pm SD ve $\mathrm{n}(\%)$ olarak verildi.

a, t-test; b, ki-kare testi.

Tablo 2. Gruplar arasında cinsel parametrelerin karşılaştırılması

\begin{tabular}{|c|c|c|c|c|c|}
\hline Parametreler & $\begin{array}{c}\text { GRUP1 } \\
\text { Kontrol (n:122) }\end{array}$ & $\begin{array}{c}\text { GRUP2 } \\
\text { Trikomonas }(n: 27)\end{array}$ & $\begin{array}{c}\text { GRUP3 } \\
B V(n: 40)\end{array}$ & $\begin{array}{c}\text { GRUP4 } \\
\text { Kandida (n:41) }\end{array}$ & $p$ \\
\hline İstek & $3,2 \pm 1,3$ & $3,1 \pm 1$ & $3,2 \pm 1,1$ & $3,2 \pm 1,1$ & $958^{a}$ \\
\hline Uyarılma & $3,6 \pm 1,3$ & $3,1 \pm 1,2$ & $3,3 \pm 1,3$ & $3,5 \pm 1,3$ &, $268^{a}$ \\
\hline Islanma & $3,9 \pm 1,3$ & $3,6 \pm 1,2$ & $3,5 \pm 1,3$ & $3,7 \pm 1,2$ &, $376^{a}$ \\
\hline Orgazm & $3,6 \pm 1,5$ & $3,4 \pm 1,5$ & $3,4 \pm 1,4$ & $3,6 \pm 1,3$ & $924^{\mathrm{a}}$ \\
\hline Tatmin & $4 \pm 1,4$ & $3,6 \pm 1,4$ & $3,9 \pm 1,3$ & $3,8 \pm 1,4$ &, $574^{\mathrm{a}}$ \\
\hline Ağrı & $3,7 \pm 1,6$ & $3,7 \pm 1,4$ & $3,3 \pm 1,4$ & $3,5 \pm 1,2$ &, $524^{a}$ \\
\hline Total FSFI skor & $22,2 \pm 6,3$ & $20,7 \pm 6,1$ & $20,9 \pm 6,8$ & $21,5 \pm 6$ &, $523^{a}$ \\
\hline FSD $(n, \%)$ & $93(40,4)$ & $23(10)$ & $33(14,3)$ & $31(13,5)$ &, $648^{b}$ \\
\hline
\end{tabular}

Veriler ortalama \pm SD ve $n$ (\%) olarak verildi. a; t-test, b; ki-kare testi. FSD: Female sexual dysfunction 
Tablo 3. Seksüel disfonksiyona neden olan risk faktörleri için lojistik regresyon analizi

\begin{tabular}{|c|c|c|c|c|c|}
\hline \multirow{2}{*}{$\begin{array}{l}\text { Parametreler } \\
\text { Koku }\end{array}$} & & \multirow{2}{*}{$\frac{\text { ODD ratio }}{, 560}$} & \multirow{2}{*}{$\begin{array}{c}p \\
, 092\end{array}$} & \multicolumn{2}{|c|}{$95,0 \%$ C.I. } \\
\hline & & & & ,286 & 1,098 \\
\hline \multirow{4}{*}{ Renk } & yok & - & 073 & - & - \\
\hline & sarı & 2,326 & 194 & ,650 & 8,326 \\
\hline & beyaz & 5,000 & 019 & 1,299 & 19,240 \\
\hline & yeşil & 3,417 & 080 & ,865 & 13,492 \\
\hline \multirow[t]{3}{*}{ Kaşıntı } & & 1,097 & ,781 & ,570 & 2,112 \\
\hline & yok & & ,331 & & \\
\hline & oks & 2,562 & ,126 & 767 & 8,558 \\
\hline \multirow[t]{4}{*}{ Doğum kontrol yöntemi } & kondom & 3,611 & 173 & ,570 & 22,897 \\
\hline & RiA & 1,296 & 692 & ,358 & 4,688 \\
\hline & Tüp lig. & 2,009 & ,276 & ,573 & 7,038 \\
\hline & yok & - & 698 & - & - \\
\hline \multirow{3}{*}{ Doğum şekli } & NSD & 640 &, 510 & 170 & 2,412 \\
\hline & sezaryen & 1,077 & 902 & ,329 & 3,529 \\
\hline & NSD+sezaryen & 970 & 963 & ,267 & 3,519 \\
\hline \multirow[t]{2}{*}{ Dismenore } & & 776 &, 505 & ,368 & 1,636 \\
\hline & $\leq$ ilkokul & - &, 010 & - & - \\
\hline \multirow[t]{2}{*}{ Eğitim durumu } & ortaokul/lise & 3,815 & ,003 & 1,574 & 9,249 \\
\hline & $\geq$ üniversite & 1,967 & 136 & ,808 & 4,785 \\
\hline Meslek durumu, çalışıyor & & 1,572 & 017 & 1,084 & 2,279 \\
\hline
\end{tabular}

Tablo 4. Semptomatik özelliklerin karşılaştırılması

\begin{tabular}{|c|c|c|c|c|c|c|c|}
\hline Parametreler & & $\begin{array}{l}\text { GRUP1 } \\
(n: 122)\end{array}$ & $\begin{array}{c}\text { GRUP2 } \\
(n: 27)\end{array}$ & $\begin{array}{c}\text { GRUP3 } \\
(n: 40)\end{array}$ & $\begin{array}{c}\text { GRUP4 } \\
(n: 41)\end{array}$ & $\begin{array}{c}\text { Total } \\
\text { (n:230) }\end{array}$ & $p$ \\
\hline \multirow{2}{*}{ Koku (n, \%) } & var & $36(15,7)$ & $17(7,4)$ & $22(9,6)$ & $18(7,8)$ & $93(40,4)$ & \multirow{2}{*}{,001 } \\
\hline & yok & $86(37,4)$ & $10(4,3)$ & $18(7,8)$ & $23(10)$ & $137(59,6)$ & \\
\hline \multirow{4}{*}{ Renk (n, \%) } & yok & $69(30)$ & $1(0,4)$ & $9(3,9)$ & $12(5,2)$ & $91(39,6)$ & \multirow{4}{*}{,000 } \\
\hline & sarı & $28(12,2)$ & $18(7,8)$ & $19(8,3)$ & $12(5,2)$ & $77(33,5)$ & \\
\hline & beyaz & $21(9,1)$ & $6(2,6)$ & $8(3,5)$ & $16(7)$ & $51(22,2)$ & \\
\hline & yeşil & $4(1,7)$ & $2(0,9)$ & $4(1,7)$ & $1(0,4)$ & $11(4,8)$ & \\
\hline \multirow{2}{*}{ Kaşıntı (n, \%) } & var & $30(13)$ & $12(5,2)$ & $14(6,1)$ & $23(10)$ & $79(34,3)$ & \multirow{2}{*}{,002 } \\
\hline & yok & $92(40)$ & $15(6,5)$ & $26(11,3)$ & $18(7,8)$ & $151(65,7)$ & \\
\hline
\end{tabular}

Veriler $n(\%)$ olarak verildi. İstatistik analiz için ki-kare test kullanıldı.

\section{TARTIȘMA}

Genel toplum verilerine baktığımızda kadınlarda seksüel disfonksiyon prevalansı \%27-70 arasında belirtilmiştir. ${ }^{[18,19]}$ Türkiye'de yapılan çalışmalar incelendiğinde bu oranlar \%43,4 ile \%48,8 arasında değişmektedir. ${ }^{[20-23]}$ Çalışmamızda akıntısı olan tüm hastalarda FSD oranı \%78,3’tür(n: 180). Depresyon, kronik hastalıklar, geçirilmiş operasyonlar, ekonomik seviye, doğum kontrol yöntemleri, çalışma durumu, ilişkisel çatışmalar, yaş, gebelik gibi birçok faktör seksüel disfonksiyon için risk faktörü olabilir. Korunma yöntemleri gebelik ve bulaşıcı hastalıklar açısından güvenli olduğu için FSD'yi azaltabilir. ${ }^{[24]}$ Oral kontraseptiflerin FSD üzerine etkisi tartışmalıdır. ${ }^{[25]}$ Kondom için ise daha çok seksüaliteyi azalttığı yönünde bulgular vardır. ${ }^{[26]}$ Çalışmamızda anlamlı olmasa da korunma yöntemleri arasında kondom FSD için en yüksek risk oranına sahiptir (OR: 3,6), teması azaltan bir yöntem için beklenen 
bir sonuçtur. ${ }^{[27]}$ Nilüfer ve ark. genital enfeksiyonların, düşük eğitim seviyesinin, çalışmıyor olmanın FSD'yi arttırdığını belirtmiştir. ${ }^{[28]}$ Artan yaş ve düşük eğitim durumu FSD için risk olarak belirtilse de aksini gösteren çalışmalar da mevcuttur. ${ }^{[25-31]}$ Gordon ve ark. da yaş, eğitim ve mesleki statüde FSD için artmış risk tespit etmemişlerdir. ${ }^{[32]} \mathrm{Biz}$ çalışmamızda beyaz renkli akıntıyı, çalışıyor olmayı ve orta düzey eğitim seviyesini FSD için risk faktörü olarak tespit ettik (Tablo 3). Toplumdan topluma değişen sosyo-kültürel yapılar çalışma sonuçlarını etkiliyor olabilir.

Vajinal akıntı, bir kadının hayatı boyunca çok sık karşılaşacağı bir problemdir ve yanma, ağrı, kaşıntı, kötü koku, disüri gibi rahatsız edici sorunlara neden olur; ancak akıntının cinsel disfonksiyonlar üzerine etkisi tartışmalıdır ve bu etkiyi inceleyen çalışmalar literatürde kısıtlıdır. Hastaların \%53'ünde seksüel disfonksiyon tespit edilen bir çalışmada vajinit oranı \%29'dur. ${ }^{[32]}$ Güngör ve ark. etyolojiden bağımsız olarak akıntının seksüalite üzerine etkisini incelediklerinde akıntısı olan gruplarda FSFI toplam skorunu anlamlı olarak yüksek bulmuşlardır ve FSD olan hasta sayısında anlamlı fark izlememişlerdir. ${ }^{[33]}$ Giraldo ve ark. vajinal kandidiyaziste total FSFI skorunun, orgazm ve tatmin skorunun kontrol grubuna göre anlamlı olarak daha düşük olduğunu tespit etmişlerdir. ${ }^{[34]}$ Biz farklı etyolojik sebepleri karşılaştırdığımız çalışmamızda akıntı grupları arasında FSFI total ve subgrup skorlarında anlamlı fark izlemedik, FSD olan hasta sayılarında da anlamlı fark görmedik (Tablo 2). Bu sonuçlar bize, farklı vajinal enfeksiyonların farklı semptomlarının olası bir FSD ile ilişkisi olmadığını düşündürmektedir. Gruplardaki hastaları ne kadar randomize etmeye çalışmış olsak ta, seksüel fonksiyon aynı anda çok farklı faktörlere bağlı olduğundan sonuçlar etkileniyor olabilir.

Vajinal enfeksiyonların semptomatolojisine göz atacak olursak belki de en rahatsız edici olanı kokudur. En sık görülen akıntı nedeni olan bakteriyel vajinozisin ön planda olan özelliği, prediktif olan kokusudur. ${ }^{[35]}$ Fakat çalışmamızda koku anlamlı olarak kontrol grubunda yüksek çıkmıştır ve 2. sırada BV grubu bulunur. Genital akıntının sebebi genelde vajinitler olsa da çok farklı sebepleri de bulunmaktadır. ${ }^{[35,36]}$ Kötü kokulu bir akıntı, kişiyi sosyal hayattan ve seksüel yaşamdan uzaklaştırabilir. ${ }^{[6]}$ Yaptığımız lojistik regresyon analizine göre koku ve FSD arasında ilişki yoktur (OR: 0,560; p: 0,092; \%95 C. I. : 0,285-1,098). Kokunun vajinal akıntı, vajinit ve enfeksiyon tipinden bağımsız da oluşabiliyor olması FSD ile ilişkisiz olmasını açılayabilir.

İlişkide ağrı, yani disparoni apayrı bir konudur. Önceden ayrı değerlendirilen disparoni, son DSM-V kriterlerine göre 'genito-pelvic pain/penetration disorder (GPPD)' başlığı altında incelenmektedir. ${ }^{[37]}$ Vajinitlerden trikomonas genelde disparoni ile ilişkilendirilir. Kandida ve BV'e bağlı vajinitler giriş ağrısına neden olabilir. ${ }^{[7]}$ Elbette akıntısı olan her hastada disparoni gelişmek zorunda değildir. ${ }^{[1]}$ Diğer enfektif ajanlara bağlı enfeksiyonlarda da (gonore, klamidya) ağrı oluşabilir ve tabiki disparoninin enfeksiyon dışında çok farklı sebepleri de vardır. ${ }^{[38-41]}$ Çalışmamızda ağrı skorunda gruplar arasında anlamlı fark yoktu, ancak enfektif grup içerisinde en yüksek trikomonas grubundaydı (Tablo 2).

Yine aynı şekilde kaşıntı özellikle kandidiyal enfeksiyonlarda görülürken ${ }^{[42]}$ çalışmamızda kontrol grubunda yüksek çıkmışıır, 2. sırada da kandida grubundadır. Çoğunlukla BV beyaz gri, trikomonas sarı yeşil, kandida beyaz akıntıyla kendini gösterir. ${ }^{[4]}$ Çalışmamızda kandida grubunda en çok beyaz, trikomonas ve BV gruplarında ise en çok sarı renkli akıntı izlendi (Tablo 4). Glehn ve ark. jinekolojik şikayetleri araşııdıkları çalışmalarında hastaların \%46'sında akıntı varken bu oran disparoni için $\% 34$, koku için $\% 33$, kaşıntı için \%28'dir ${ }^{[1]}$. Tüm hastaların (\%100) vajinal akıntıya sahip olduğu çalışmamızda kaşıntı oranı \%34,3; koku oranı ise \%40,4'tür.

$\mathrm{Bu}$ çalışma, en sık görülen 3 farklı vajinal enfeksiyon tipinin cinsel fonksiyonlar üzerine etkisini karşılaştırmalı olarak bir arada inceleyen ilk prospektif çalışmadır. Vajinal akıntının FSD'ye etkisi net olmadığından özellikle akıntısı olan hastalardaki seksüel fonksiyonları ve tipler arasındaki farkları incelemek istedik. Yine de akıntısı olmayan hastalardan oluşan bir kontrol grubunun olmaması, gruplardaki hasta sayıların az olması, daha farklı enfektif ajanların (klamidya, gonore) ve mikst enfeksiyonların araştırılmaması çalışmamızın eksiklikleri arasında sayılabilir. Daha geniş çaplı ve kontrol grubunun da olduğu büyük çalışmalarla verilerin desteklenmesi gerekmektedir. Ek olarak, diğer bir sınırlama, tanı için pap-smear kullanımıdır. Pap-smear yöntemi enfeksiyöz ajanların tespitinden altın standart değildir. Bazı çalışmalarda pap-smear'ın trichomonas vaginalisis için \%98 ve \%96, BV için \%57 ve \%94 ve candida için $\% 31$ ve \%98,5 duyarlılık ve özgüllüğ̈̈nün olduğu gösterilmiştir. ${ }^{[14-17,39]}$ Ancak daha ucuz, pratik ve rutin kullanımı nedeniyle pap-smear yöntemi çalı̧̧mamızda tercih edildi. Aynı zamanda tanıyı güçlendirmek adına pap-smear testi sonucunu vajinal muayene bulgularımızla ilişkilendirerek grupları oluşturduk. Bu şekilde teşhis doğruluğumuzu artırmaya çalıştık.

\section{SONUÇ VE ÖNERILER}

Sonuç olarak; genital ve erojen bölgelerin etkileşime girmesiyle beyinde yaşanan seksin çok farklı etkene aynı anda ve bir arada bağlı olmasından ötürü tek başına bir faktörün 
cinsel yaşama etkisini net ortaya koymak güçtür. Bu minvalde düşündügümüzde akıntının FSD’ye neden olduğu kesin olmamakla birlikte, akıntılı hastalarda en sık görülen vajinit ajanları (trikomonas, $\mathrm{Bv}$, kandidiyazis) arasında FSD açısından bir fark görülmemektedir. Bu konuda geniş vaka sayısına sahip randomize kontrollü çalışmalara ihtiyaç vardir.

\section{Etik Kurul Onayı}

Çalışma, Kartal Eğitim ve Araştırma Hastanesi Etik Kurulu tarafından onaylandı. (onay tarihi ve sayısı: 2016/2016/514/88/12).

\section{Hakem Değerlendirmesi}

Dış bağımsız.

Çıkar Çatışması

Yazarlar çıkar ilişkisi olmadığını beyan etmişlerdir.

\section{Finansal Destek}

Herhangi bir mali destek alınmamıştır.

\section{Ethics Committee Approval}

The study was approved by Kartal Training and research Hospital Ethics Committee. (date and number of approval: 2016/2016/514/88/12).

\section{Peer-review}

Externally peer-reviewed.

\section{Conflict of Interest}

No conflict of interest was declared by the authors.

\section{Financial Disclosure}

No financial support has been received.

\section{KAYNAKLAR}

1. de Paula Von Glehn M, Sidon LU, Machado ER. Gynecological complaints and their associated factors among women in a family health-care clinic. J Fam Med Prim Care 2017;6:88-92. [CrossRef]

2. Paladine HL, Desai UA. Vaginitis: Diagnosis and Treatment. Am Fam Physician 2018;97:321-9. https://www.aafp.org/ afp/2018/0301/p321.html

3. JR Berman. Physiology of female sexual function and dysfunction. Int J Impot Res 2005;17:S44-51. [CrossRef]

4. Hainer LB, Gibson MV. Vaginitis: Diagnosis and Treatment. Am Fam Physician 2011;83:807-15. https://www.aafp.org/ afp/2011/0401/p807.html

5. Van Lankveld J, Granot M, Weijmar Schultz W, Binik YM, Wesselmann U, Pukall CF, et al. Women's sexual pain disorders. J Sex Med 2010;7:615-31. [CrossRef]

6. Subramanian C, Nyirjesy P, Sobel JD. Genital malodor in women: a modern reappraisal. J Low Genit Tract Dis 2012;16:49-55. [CrossRef]

7. Heim LJ. Evaluation and Differential Diagnosis of Dyspareunia. Am Fam Physician 2001;63:1535-44. https://www.aafp.org/ afp/2001/0415/p1535.html

8. Hodges AL, Holland AC. Common Sexually Transmitted Infections in Women. Nurs Clin North Am 2018;53:189-202. [CrossRef]

9. Dina Khnaba, Rostom S, Lahlou R, Bahiri R, Abouqal R, HajjajHassouni N. Sexual dysfunction and its determinants in Moroccan women with rheumatoid arthritis. Pan African Med J 2016;24:113. [CrossRef]

10. Rabiepoor S, Khalkhali HR, Sadeghi E. Whatkind of sexual dysfunction is most common among overweight and obese women in reproductive age? Int J Impot Res 2017;29:61-4. [CrossRef]
11. Rosen R, Brown C, Heiman J, Leiblum S, Meston C, Shabsigh R, et al. The Female Sexual Function Index (FSFI): a multidimensional self-report instrument for the assessment of female sexual function. J Sex Marital Ther 2000;26:191-208. [CrossRef]

12. Öksüz E, Malhan S. The Reliability and Validity of Turkish Version of Female Sexual Function Index. Sendrom 2005;17:54-60. https:// www.researchgate.net/publication/285879607_Reliability_and_ validity_of_the_Female_Sexual_Function_Index_in_Turkish_ population

13. Hart G. Factors associated with trichomoniasis, candidiasis and bacterial vaginosis. Int J SRN AIDS 1993:4:21-5. [CrossRef]

14. Loo SK, Tang WY, Lo KK. Clinical significance of Trichomonas vaginalis detected in Papanicolaou smear: a survey in female Social Hygiene Clinic. Hong Kong Med J 2009;15:90-3. https://www. hkmj.org/abstracts/v15n2/90.htm

15. Tokyol C, Aktepe OC, Cevrioğlu AS, Altindiş M, Dilek FH. Bacterial vaginosis: comparison of Papsmear and microbiological test results. Mod Pathol 2004;17:857-60. [CrossRef]

16. Audisio T, Pigini T, de Riutort SV, Schindler L, Ozan M, Tocalli C, Bertolotto P. Validity of the Papanicolaou Smear in the Diagnosis of Candida spp., Trichomonas vaginalis, and bacterial Vaginosis. J Low Genit Tract Dis 2001;5:223-5. [CrossRef]

17. Wiese W, Patel SR, Patel SC, Ohl CA, Estrada CA. A meta-analysis of the Papanicolaou smear and wet mount for the diagnosis of vaginal trichomoniasis. Am J Med 2000;108:301-8. [CrossRef]

18. Kucukdurmaz F, Inanc $Y_{1}$, Inanc Yu, Resim S. Sexual dysfunction and distress in premenopausal women with migraine: association with depression, anxiety and migraine-related disability. Int J Impot Res 2018;30:265-71. [CrossRef]

19. Carranza-Lira $S$, Núńez F. Sexual dysfunction prevalence in a group of pre- and postmenopausal Mexican women. Menopause Review/ Przeglad Menopauzalny 2018;17:39-42. [CrossRef]

20. Ege E, Akın B, Arslan SY, Bilgili N. Prevalence and risk factors of female sexual dysfunction among healthy women. TUBAV 2010;3:137-44. https://dergipark.org.tr/tr/download/ article-file/200874

21. Aslan E, Beji NK, Gungor I, Kadioglu A, Dikencik BK. Prevalence and risk factors for low sexual function in women: a study of 1009 women in an out patient clinic of a university hospital in Istanbul. J Sex Med 2008;5:2044-52. [CrossRef]

22. Cayan S, Akbay E, Bozlu M, Canpolat B, Acar D, Ulusoy E. Theprevalence of female sexual dysfunction and potential risk factors that may impair sexual function in Turkish women. Urol Int 2004;72:52-7. [CrossRef]

23. Oksuz E, Malhan S. Prevalence and risk factors for female sexual dysfunction in Turkish women. J Urol 2006;175:654-8. [CrossRef]

24. Higgins JA, Hoffman S, Graham CA, Sanders SA. Relationships between condoms, hormonal methods, and sexual pleasure and satisfaction: an exploratory analysis from theWomen'Well-Being and Sexuality Study. Sex Health 2008;5:321-30. [CrossRef]

25. Burrows LJ, Basha M, Goldstein AT. Theeffects of hormonalcontraceptives on femalesexuality: A review. J Sex Med 2012;9:2213-23. [CrossRef]

26. Higgins JA, Hirsch JS. The pleasure deficit: revisiting the "sexuality connection" in reproductive health. Perspect Sex Reprod Health 2007;39:240-7. [CrossRef]

27. Randolph ME, Pinkerton SD, Bogart LM, Heather Cecil H, Abramson PR. Sexual Pleasure and Condom Use. Arch Sex Behav 2007;36:844-8. [CrossRef] 
28. Erbil N. Prevalence and Risk Factors for Female Sexual Dysfunction Among Turkish Women Attending a Maternity and Gynecology Outpatient Clinic. Sex Disabil 2011;29:377-86. [CrossRef]

29. Fajewonyomi BA, Orji EO, Adeyemo AO. Sexual dysfunction among female patients of reproductive age in a hospital setting in Nigeria. J Health Popul Nutr 2007;25:101-6. https://www.ncbi. nlm.nih.gov/pmc/articles/PMC3013270/

30. Sidi H, Puteh SE, Abdullah N, Midin M. The prevalence of sexual dysfunction and potential risk factors that may impair sexual function in Malaysian women. J Sex Med 2007;4:311-21. [CrossRef]

31. Singh JC, Tharyan P, Kekre NS, Singh G, Gopalakrishnan G. Prevalence and risk factors for female sexual dysfunction in women attending a medical clinic in South India. J Postgrad Med 2009;5:113-20. [CrossRef]

32. Gordon D, Gardella C, Eschanbach D, Mitchell MC. High prevalence of sexual dysfunction in a vulvovaginal specialty clinic. Low Genit Tract Dis 2016;20:80-4. [CrossRef]

33. Gungor AN, Uludag A, Sahin M, Gencer M, Uysal A. Gungor AN, et al. Effects of vaginal discharge on female sexual function. Int J Gynaecol Obstet 2014;124:27-9. [CrossRef]

34. Giraldo PC, Polpeta NC, Juliato CRT, Yoshida LP, Gomes do Amaral RL, Eleutério J Jr. Evaluation of sexualfunction in Brazilian women with recurrent vulvovaginal candidiasis and localized provoked vulvodynia. J Sex Med 2012;9:805-11. [CrossRef]
35. Anderson MR, Klink K, Cohrssen A. Evaluation of vaginal complaints. JAMA 2004;291:1368-79. [CrossRef]

36. Doty RL, Ford M, Preti G, Huggins GR. Changes in the intensity and pleasantness of human vaginal odors during the menstrual cycle. Science 1975;190:1316-8. [CrossRef]

37. Akarsu RH, Beji NK. Kadın cinsel fonksiyon bozuklukları sınıflandırılmasında DSM-V kapsamında yapılan değişiklikler. Androloji Bülteni 2016;18:133-7. [CrossRef]

38. Wright JJ, O'Connor KM. Female Sexual Dysfunction. Med Clin North Am 2015;99:607-28. [CrossRef]

39. Wiese W, Patel SR, Patel SC, Ohl CA, Estrada CA. A meta-analysis of the Papanicolaou smear and wet mount for the diagnosis of vaginal trichomoniasis. Am J Med 2000;108:301-8. [CrossRef]

40. Karakuş R, İsmailov H, Namazov A, Arınkan SA, Temizkan O, Anğın AD, Karakuş SS. Research of the efficacy of topical local anesthesia for hysteroscopy: a randomised-controlled trial Med Bull Sisli Etfal Hosp 2014;48:86-91. [CrossRef]

41. Aşııı̆ğlu O, Temizkan O, Arıcı B, Aşıcıoğlu BB. Clinical Characteristics and Outcomes of Laparoscopic Surgery in Ovarian Endometrioma Cases Treated at a Gynecology Clinic. Med Bull Sisli Etfal Hosp 2018;52:1-5. [CrossRef]

42. Carrillo-Meléndrez H, Villamil-Cerda D, Espinoza-Hernández J, Lacy-Niebla RM. Vulvar pruritus: determination of the most common causes and their treatments. Ginecol Obstet Mex 2015;83:179-88. https://pubmed.ncbi.nlm.nih.gov/26058171/ 